\title{
IMPACT OF COMPUTER - BASED CONCEPT MAPPING ON DEVELOPING READING PERFORMANCE OF EFL SECONDARY SCHOOL STUDENTS
}

\author{
By \\ Dr.Sahar Abdul Hameed Shoshan \\ Lecturer of ELT \\ Higher Institute of Languages \\ 6 October University
}

DOI: $10.12816 / 0052309$

مجلة الدراسات التربوية والانسانية ـ كلية التربية ـ جامعة دمنهور

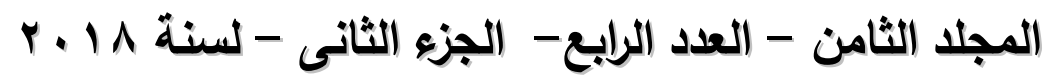




\section{IMPACT OF COMPUTER - BASED CONCEPT MAPPING ON DEVELOPING READING PERFORMANCE OF EFL SECONDARY SCHOOL STUDENTS}

\section{Dr.Sahar Abdul Hameed Shoshan}

DOI: $10.12816 / 0052309$

This study has examined two types of instructions for two groups: concept mapping reading instruction group and traditional reading instruction group. The purpose of the study was to investigate whether there were differences between the two instructions in three reading areas: main idea reading, subordinate idea reading and reading between the lines. Participants included $(n=40)$ first year secondary EFL students for the two groups. Statistical findings using independent samples t-test have answered the research questions that there was no significant difference in the three reading areas between the two instructions. However, one-way ANOVA revealed significant difference that concept mapping participants read better in main idea and subordinate idea readings. The attitude survey revealed significant differences that concept mapping participants were in favor of functions of textbook and technology and roles played by instructors. Future research should investigate the possibilities of combining the strong points of traditional instruction with the advantages of educational technology in four learning areas. First, longer training periods and more training opportunities could be provided for EFL students to enhance technological learning. Second, traditional instruction could be combined with technology so as to meet the needs of EFL students. Third, in a technological class, students could be helped to learn from multiple sources as textbooks, teachers, students and technology instead of single learning source just a teacher or technology. Fourth, workshops could be provided for instructors to enhance technological instruction. 
اثر خرائط المفاهيم الحاسوييـة على تنمية الاداء فى القراءة فى اللفة الانجليزية كلغة اجنبية لطلاب المدرسة الثانوية

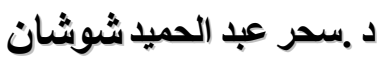

DOI: $10.12816 / 0052309$

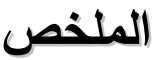

تتــاول هذه الدراسـة نمطين مـن تـريس القـراءة : الاول قـائم على خـرائط المفاهيم الحاسوبية و الثانى على الطريقة التقليدية. وقد تم اختيار مجموعة هلدئ

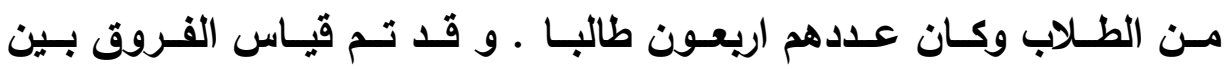
المجموعتين فى ثُلاث مجالات وهى : تعديد الفكرة الرئيسية ثم تحديد الفكرة الثانوية واخيرا قراعة مابين السطور • و استخدام تحليل التباين بين المجموعتين اظهر ان هناك فروق ذات دلالة بين الطلاب الذين استخدموا خرائط المفاهيم الحاسويية وكانوا افضل فى الفهم القرائى للفكرة الرئيسية و الثانوية من طلاب المجموعة التى درست بالطريقة التقليدية. ومن اهم التوصيات هو الجمع بين الطريق التقليدية و المعتده على التكنولوجيا لتلبية حاجات الطلاب وكذلك تعدد مصادر التعلم للطلاب عن طريق الكتب و المعلمون والطلاب و التكنولوجيا بدلا

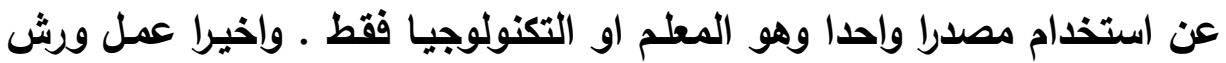
عمل للمعلمين للاسفادة القصوى من التكنولوجيا فى التدريس. Key words:

Computer-concept mapping - Reading performance 


\section{INTRODUCTON}

The use of concept mapping in instructional practice is not new. It has been researched and practiced at various educational levels since it was first developed by Novak in the 1970s, and it is being used more and more in scientific studies and in other forms of research as a tool for organizing and representing knowledge (Novak, 1998). The literature in this field reflects an established and well-researched body of knowledge showing that concept mapping fosters learning by encouraging students to think both deeply and critically. Concept mapping instruction helps students learn better in various subjects and at various contexts. It is helpful in generating ideas in learning by communicating complex ideas and aiding learning by explicitly integrating new and old knowledge. Concept mapping improves reading comprehension in helping students to cultivate and understand new information by combining the new with the old. Concept mapping, as an efficient instructional process, is inclusive and is an activity that facilitates cooperative learning. Also, it encourages meaningful learning and enhances student learning cognitively and constructively. This instructional practice has received much attention in the educational field.

In English as a Foreign Language (EFL), concept mapping theory and instruction related to it are seldom developed or put into practice in the classroom and applied in real life. EFL instruction in many Egyptian schools is mostly accomplished through a traditional learning model. Students are either book-dependent or instructordependent. As a result of this approach to learning, many learners are passive in EFL learning. Students find themselves uncomfortable when they are forced into taking responsibility for their own learning, setting their own pace, seeking out resources and learning independently and collaboratively. They are uncomfortable in reading without stopping to consult a dictionary or other resources. A student may not realize that he is one of the most important resources to rely on in learning. Assimilation learning theory by Ausubel (1963, 1964), schema theory by Coady (1979) and concept-map theory by Novak (1981, 1984, 1993, 1998) are included in this study that will investigate the use of concept mapping as an efficient tool in linguistic processing among EFL students. It asserts that concept- mapping-aided-reading instruction encourages EFL students to learn by applying their background knowledge to organize information and to explore the relationships among the narrative material, background knowledge, and their 
understanding of it. Meaningful learning occurs when these are commingled.

\section{Statement of Problem}

In Egypt, the majority of EFL learners study and learn English to access reading materials such as scientific, medical, literary and other narrative works. Reading is considered an essential skill that all EFL learners must be proficient with if they want to succeed in advanced study or study at the university. However, it is this very ability and skill that remains a significant challenge for many EFL learners.

Often many EFL readers approach a reading assignment by puffing all their effort and concentration into the passages they read. The principal strategy is to slowly and carefully read the text word by word. While reading and encountering a new word in reading, they stop reading immediately and consult the dictionary for the meaning of the word. This reading behavior not only slows down their reading speed, but also hinders their reading comprehension. Many of them know very little about using their prior knowledge into reading because they are not familiar with the idea that the readers/learners construct meaning from the context by "bringing their information, knowledge, emotion, experience, and culture to the printed word" (Brown, 1994, p. 284). Faced with reading challenges among EFL learners, this study investigated whether Novak's carefully structured concept mapping processes cause EFL readers to use their background knowledge while reading English, and determined if the use of their prior knowledge associated with the reading material and improved their overall reading comprehension.

\section{Research Questions}

The study used a quantitative research method to assess concept mapping and traditional reading instructions in three reading areas: main idea reading, subordinate idea reading and reading between the lines of EFL first year secondary school students $\quad(n=40)$ who developed concept maps to those who did not. It also assessed students' attitudes of the two instructions. Based on the three reading areas and attitudes of students, the study addressed three general questions connected with concept mapping and traditional instruction in classes taken by EFL students:

1. Is there any difference in comprehension on main idea and subordinate idea readings between concept mapping and traditional instruction?

2. Is there any difference in comprehension on reading between the lines between concept mapping and traditional instruction?

Doi: 10.12816/0052309 
3. Is there any difference in participants' attitudes between concept mapping and traditional instruction?

\section{Significance of Study}

To improve student reading comprehension and to change student reading behavior from book-dependence to an active one that applies prior knowledge to the reading process, concept mapping reading instruction may free learners from totally relying on linguistic items and grammatical structures for comprehension. The study results may reveal significance in student reading comprehension using concept mapping instruction in the teaching of English as a foreign language. If this occurs, the study proposes to make the following contributions to the literature:

First and foremost, the study contributes to the significance of understanding by more EFL professionals of concept mapping theory and concept mapping instruction and provides them with another process to reinforce reading in their instructional practice. Information obtained through this study will add to the body of knowledge regarding concept mapping instruction.

Significance in changing learners' reading habits from totally traditional, passive book or instructor-centered to an active, autonomous and cooperative-centered habit is the second possible contribution from this study. EFL reading instruction is mainly a practice of traditional learning, emphasizing grammar learning, vocabulary learning and even a mental translation from the mother tongue into the target language and from the target language into the mother tongue. Classroom activity is mainly dialogues and drills, repetition and memorization, and pattern practice. Much vocabulary is taught in the form of lists of isolated words . Long elaborate explanations of the intricacies of grammar are given. Grammar provides the rules for putting words together, and instruction often focuses on the form and inflection of words. Curriculum assessment in this instruction is a graded assessment of syntax and contrastive analysis. A student's role in class is that of a passive organism that can be directed by skilled training techniques to repeat and produce correct responses while the instructor plays a central role, dominates class time, provides models and controls direction and pace .

By using concept mapping instruction, the study seeks to determine if EFL learners can change their reading behavior from passive and book dependency to a more active, autonomous and cognitively-based learning behavior which will improve reading 
comprehension by bringing prior knowledge to the forefront as suggested by theories of assimilation, schema and concept mapping. Based on these theories, concept mapping reading instruction regards language learning as a system for the expression of meaningful reconstruction which involves the student as a whole person by combining his culture, education and prior knowledge. This instruction involves real communication, carries out meaningful tasks and uses prior knowledge in reading which is meaningful to the learners. The instruction encourages classroom activities that engage learners in communication, collaboration, involving information sharing, negotiation of meaning, interaction and problem solving. Students, in this instruction, play roles of negotiator, interactor, designer giving as well as taking knowledge while the instructor plays roles of facilitator of the learning process, participant, texts and needs analyst, counselor and process manager to help students (Nunan, 1989). Teaching materials are primarily task-based authentic readings which are effective and meaningful in promoting concept map development and student learning.

\section{Definitions of Terms}

Active reading habit. A kind of reading behavior that applies one's background knowledge into full play in reading.

Background knowledge. A personal reservoir of information on a variety of topics; information retained in one's long-term memory; information that is essential to understanding a situation or problem.

Concept mapping. A concept map is a special form of diagram for exploring knowledge and gathering and sharing information. Concept mapping is the strategy employed to develop a concept map. A concept map consists of nodes or cells that contain a concept, item or question .

Computer-based concept mapping . A software usually allows the user to change his or her map to different electronic formats ( e.g. from outline to graphic). These electronic formats can then be stored, sent, manipulated, used, printed, and deleted like any computer file.

Prior knowledge. The total of an individual's knowledge at any given time; knowledge that students gained in life before the current topic was introduced; knowing that stems from previous experience. Note: prior knowledge is a key component of schema theories of reading and comprehension.

\section{Background to Study}

This review discusses learning theories that establish the basis for the study. The first part of the literature review centers on universal human learning theories and constructivist philosophy because these theories are universally believed to describe and explain human

Doi: 10.12816/0052309 
learning. The second part traces reading and schema theories which exert an influence on EFL learning and reading as discussed in the study.

\section{Human Learning Theories}

In bringing learning to a higher level with concept mapping instruction for the second language students, it has been discovered that the cognitive domain of human behavior is of key importance in the acquisition of both a first and a second language (Brown, 1994). The processes of perceiving, judging, knowing, and remembering are central to the task of internalizing a language. In this human learning theory section, the researcher look at cognitive processes by examining cognitive learning theories, and constructivist guidelines. These two are addressed because each one is of great importance to the leaning of an additional language.

\section{Cognitive Learning Theory}

Cognitive psychological principles assert that learning is a process which happens in the mind of a learner, through which the learner interprets, evaluates, synthesizes, and transfers knowledge to meaningful contexts. The theory manifests the importance of the human mind, memory, ability to comprehend, mental schemata, learner attitudes and motivation. The cognitive school of learning has since influenced instruction and learning in such a way that it is still one of the backbone learning theories. Among these learning theories, the meaningful learning theory by Ausubel (1963) is reviewed on which concept-map instruction of this study is based. Ausubel's (1963) assimilation learning theory has been proven to be effective in any learning context and conditions - either personal or school, first language or second language. It addresses cognitive learning or the use of knowledge which has significant implications for EFL concept mapping instruction that will be addressed in detail later.

Ausubel describes that "meaningful learning is a process in which new information is related to an existing relevant aspect of an individual's knowledge structure" (Novak, 1998, p. 51). It is this relating of existing knowledge to new information that accounts for a number of phenomena: the acquisition of new meanings, retention, the psychological organization of knowledge as a hierarchical structure, and the eventual occurrence of forgetting. As new information enters the human mind, it interacts with knowledge subsumed as a conceptual system. The cognitive learning theory directly connects with the present 
study and it consists of three basic requirements, which, for the sake of a better understanding, are visually mapped below:

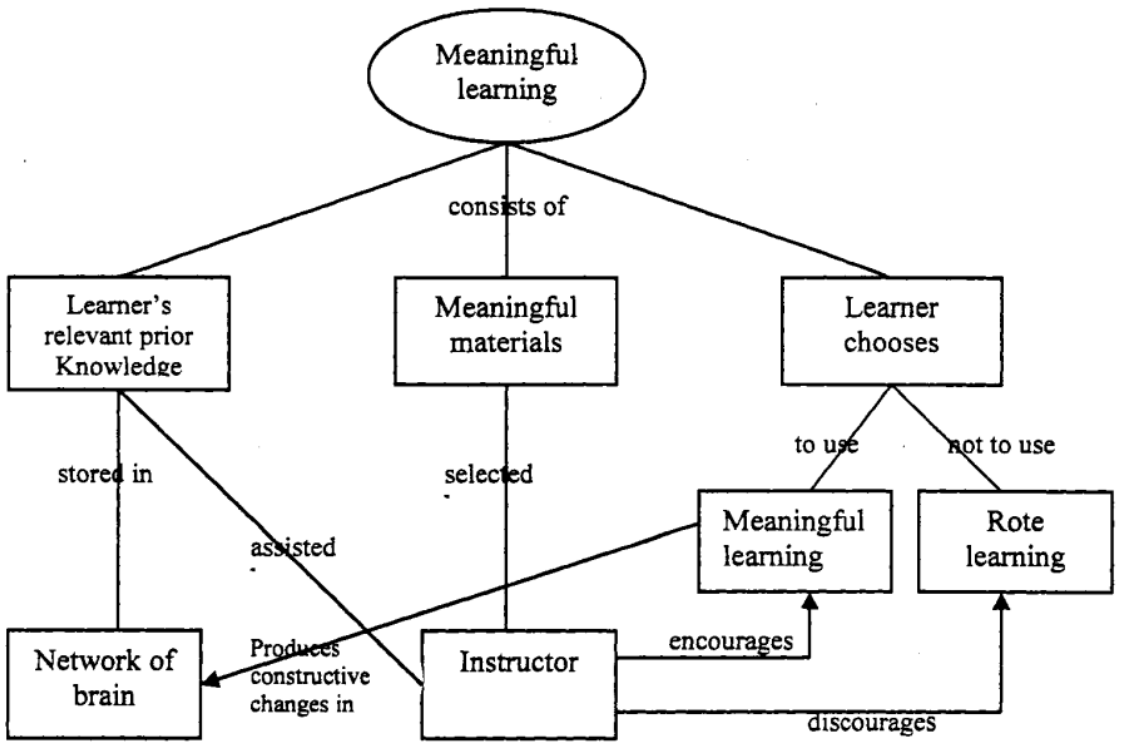

Figure (1) Novak's Concept Map for Meaningful Learning

Ausubel's (1963) meaningful learning theory emphasizes that any learning situation can be meaningful if learners have the ability or disposition to relate the new task to what they already know; and the learning task itself is potentially meaningful to the learners' structural knowledge. The second method of establishing meaningfulness is a potentially powerful factor in human learning. Things can be made meaningful if necessary and if we are strongly motivated to do so. Concepts learned meaningfully are retained longer and some can even be retained for a lifetime. Concomitantly as that of behavior learning theory, Ausubel's learning theory has made tremendous contributions to both learning and instruction. For this reason, the investigator reviews it and regards the theory as the foundation for EFL concept map instruction of this study.

Novak (1978) rediscovered Ausubel' theory and revealed its educational implication of meaningful learning when he first created a concept map to help his students to learn in the 70s. Since then, meaningful learning theory and concept mapping instruction have been researched and applied in various educational fields. Past research has demonstrated that both theories by Ausubel and Novak have beneficial effects on memory and improve student learning. The point of view is also compatible with the theory of EFL communicative language teaching of Krashen (1993), which stresses that while learning a second

Doi: 10.12816/0052309 
language, learners need to actively interact with the external environment and integrate new information with the information already stored in their memory.

\section{Constructive Philosophy}

Constructivist philosophy is basically "an educational philosophy or a set of principles within a larger category of philosophies that is described as "rationalism" (Smith \& Ragan, 1999, p. 14). Constructivist principles are based on observation and scientific study about how people learn. It is characterized by the belief that reason is the primary source of knowledge and that knowledge is constructed rather than discovered or given. Most rationalists suggest that there is not a single reality to be discovered, but that each individual has constructed his/her own personal reality.

In the classroom, the constructivist view of learning has its own special instructional practices. Generally speaking, constructivist principles encourage and engage students to learn actively by applying technological techniques, experiments, or real-world problem solving to create more knowledge and then to reflect on and talk about what they are doing and how student understanding is changing (Smith \& Ragan 1999). Constructivist principles emphasize learners' cooperative learning, autonomy of learning, authentic learning, and authentic assessment ( figure 2 ). In other words, a learner plays a central role in class, while the instructor functions as a knowledge adviser, information provider, and classroom organizer. Because this principle stresses that learning always occurs in some context and context in turn affects learning, the best context for an EFL learner to learn English might be in the real context of an English speaking context so that this learner can learn real, purposeful, and meaningful language, which is useful and effective for him/her to communicate and work with native speakers. 


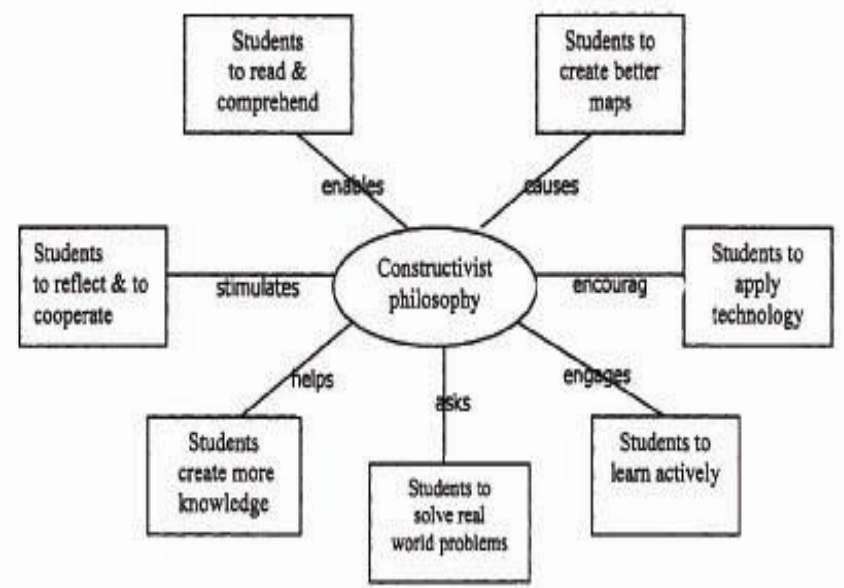

Figure( 2 ) Constructivist Philosophy

Traditional EFL methods for teaching reading at the secondary level employ a teacher-centered format of instruction in which the majority of students are passively listening to the instructor, taking notes and repeating what the book or the instructor says. Constructivist views of learning and instruction challenge the practice of traditional instructional practice by emphasizing the need of learners to play an active role in constructing knowledge and being responsible for their learning. This principle has useful classroom implications and practical applications to transfer knowledge from the classroom into the real world, manifesting the kind of learning that concept mapping in reading instruction can obtain, for it transforms the learner from a passive repeater of knowledge of books to an active creator of new knowledge. It engages a learner from an isolated single person to an active studentcentered learning group. It changes a learning habit from bookdependent to an active and constructivist learner. The emerging technology applications in classroom communication systems offer a promising tool for helping instructors create a more interactive and student-centered classroom (Dufresne, Gerace, Lwonard, Mestre \& Wenk, 1996).

\section{Theories on Second Foreign Language Reading}

Theories of reading in a second/ foreign language are influenced from that of reading in one's first language. Although insights obtained from first language reading have provided us with valuable understandings of the general reading process, many questions remain unanswered, such as: is the reading process between first language reading and second language reading the same? Can reading strategies

Doi: 10.12816/0052309 
in the first language be transferable to second language reading? The following is a review on EFL/ESL reading in tradition and EFL/ESL reading in technology.

\section{Goodman 's Reading: A Psycholinguistic Guessing Game}

During the past decade, EFL reading theory has come under the influence of psycholinguistics and the psycholinguistic reading model of Goodman (1967, 1971, 1973). He describes reading as a "psycholinguistic guessing game" (Goodman, 1967, p. 126) in which the "reader reconstructs, as best as he can, a message which has been encoded by a writer as a graphic display" (Goodman, 1971, p. 135). Goodman views this act of the construction of meaning as a constant process of sampling from the text, predicting, testing and confirming or revising those predictions, and sampling further (Goodman, 1971, 1973). Goodman's reading model argues that the "reader need not use all of the textural cues and the better the reader is able to make correct predictions, the less confirming via the text is necessary, that is, the less visual perceptual information the reader requires" (Goodman, 1971, p. 135). He states, "the reader does not use all the information available to him. Reading is a process in which the reader picks and chooses from the available information only enough to select and predict a language structure which is decodable" (Goodman, 1973, p. 164).

These views are widely accepted in EFL/ESL reading because the theory captures the spirit of the bottom-up side of the process of decoding meaning from the written words. This theory requires readers to recognize a large number of linguistic items before using them in their linguistic data processing mechanisms to cause order on these signals. This data-driven processing requires a good command of the language itself. Then, the reader chooses from among all this information the data that make sense, that is coherent, and that is meaningful. Basically, all reading involves a risk-a guessing game, because readers must, through this puzzle-solving process, infer meaning, decide what to retain, and move on (Goodman, 1973). Goodman's theory is important in that it stresses both sides that influence reading comprehension: a solid foundation in the EFL on its vocabulary, grammar, idiomatic usages, sentence structure as well as reading skills which are universally found in most languages and constitutes little, if any, difficulty for EFL students.

\section{Coady 's Reading Theory}

As early as the late 1970s, Coady (1979) suggested a reading model for EFL/ESL in which a reader's background knowledge 
interacts with conceptual abilities and process strategies to cause comprehension. This theory aligns with schema and concept mapping theories in how background knowledge is employed and influences comprehension. The simple figure below ( Figure 3 ) explains the reading theory for EFL readers.

\section{Conceptual Background Ability Knowledge Process / Strategies}

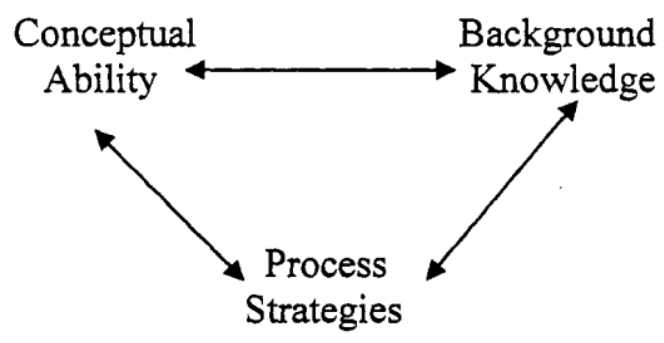

\section{Figure (3) Coady's Reading Theory}

Conceptual ability in this reading theory means general intellectual ability of the reader. Processing strategies explain various subcomponents of reading ability, and background knowledge, according to Coady "become[s] an important variable when we notice, as many have, that students with a western background of some kind learn English faster, on the average, than those without such a background" (Coady, 1979, p. 7).

Coady's reading theory is meaningful, for it suggests a reading strategy that holds important, functional background knowledge which is a key skill that may be able to compensate for certain learning deficiencies among some EFL readers. This reading theory has several elements in common with both Ausubel's assimilation learning theory and concept mapping theory that speak to the efficient comprehension of narrative materials that require the ability to relate the textual material to one's own real world knowledge (Novak, 1981, 1984).

\section{Schema Theory and Background Knowledge}

Schema theory is a framework for the mental representation of knowledge. Schema is a significant notion in understanding the knowledge structure of our brains. What we know exists as schematic hierarchies and this prior knowledge is activated when we encounter new information. There are schemata representing our knowledge about 
all concepts: those underlying objects, situations, events, sequences of events, actions and sequences of actions. Schema contains the network of interrelations that is believed to hold the constituents of the whole of a person's prior experience and knowledge. It will serve this person if he/she is willing to activate it with new knowledge.

The role of background knowledge in language comprehension (Rumelhart \& Andrew, 1977) has as one of its fundamental principles that any text, either spoken or written, does not by itself carry meaning. Rather a text only provides directions for the listeners or readers as to how they should trace and construct meaning from their own previously acquired knowledge. According to schema theory, comprehending a text is an interactive process between the reader's background knowledge and the text. Efficient comprehension requires the ability to relate the textual material to one's own knowledge. Comprehending words, sentences, and entire texts involve more than just relying on one's linguistic knowledge as Anderson (1977) points out, "every act of comprehension involves one's knowledge of the world" (p. 365).

It would be productive and meaningful if reading instruction can activate a reader's psycholinguistic processing, background knowledge with conceptual abilities and processing strategies brought into full play and a reader-centered reading model that encourages the reader to read actively and constructively. In some cases, a reader fails to comprehend because too much attention was given to the language details and language proficiency and not enough to what prior knowledge and skills the reader brought to reading and comprehending the material. Both psycholinguistic and schema reading offer better strategies than traditional reading instruction in these areas, and they have paved the way for a new reading model, reading with technology that offers learners new reading strategies and experiences that activate them to bring their prior knowledge into full play and encourage them to learn actively, cooperatively, and constructively.

\section{Novak's Concept Map Theory}

The central idea of concept mapping theory is meaningful learning. The three basic requirements for meaningful learning is the interplay among the learner, teacher, and knowledge. Students choose to learn meaningfully, but the instructor can facilitate this meaningful learning by using tools such as concept maps. Based on Ausubel's assimilation and meaningful learning theory, Novak (1981, 1984) studied concept mapping technique and developed a concept map to help students to solve problems in learning meaningfully and to help 
instructors to teach more effectively. According to Novak (1998), "meaningful learning is a process in which new information is related to an existing relevant aspect of an individual's knowledge structure" ( $p$. 51 ), as the mind organizes information in a top-down manner. To Novak, problem solving is "a function of two independent traits, knowledge stored in the mind and information processing of new learning, where integration of new and old knowledge is a function of both the quantity and the quality of cognitive structure organization" ( $p$. 50). The first of Novak's concept map is a format of top-down diagram that visually demonstrates how a student understands among the concepts and relationships.

A concept map is "the identification of concepts... and the organization of those concepts into a hierarchical arrangement from the most general and most inclusive to the least general and most specific concept" (Novak, 1981, p. 3). A concept map basically is made up of the following steps:

1. Decide on the words representing concepts to be included in the concept map and decide on the main idea to be put into the top level of the map.

2. Cluster concepts in the concept map according to two criteria: concepts that are horizontally related and concepts that are hierarchically interrelated.

3. Organize concepts from the most inclusive to the most concrete and specific.

4. Link concepts related horizontally together with boxes and lines.

5. Link concepts related vertically together with boxes and lines.

6. Use proper connective words to make sense of each line or box. The following concept map ( figure 4 ) is constructed according to the rules explained above. It includes functions of concept maps and visually makes complicated subjects simpler and enjoyable. 


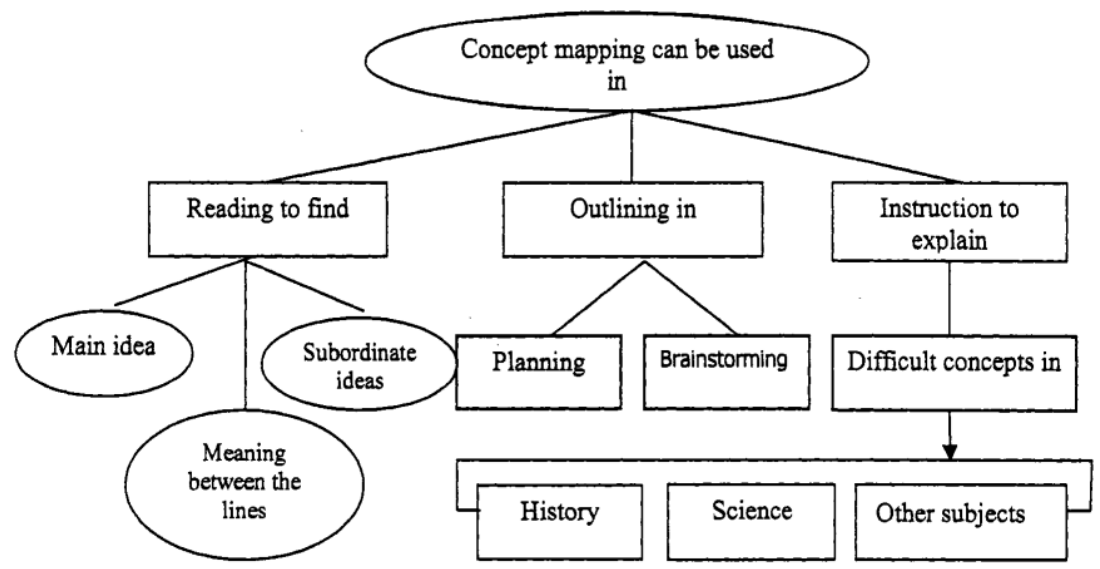

Figure (4) Concept Map for Learning and Instruction

Novak's first concept map in the 70s confirms the effectiveness of concept mapping in helping students to learn and to organize knowledge. Since then, varieties of concept mapping research have been conducted in many other areas including social studies, language arts, mathematics, multimedia planning tools, and teaching tools. In language learning, Graesser and Clark (1985) created an analysis of argument format using detailed concept maps with eight node types and four link types. In science history, various usages of concept maps have been used to represent the conceptual processing change (Nersessian, 1989). Concept maps have been used in policy studies to give a visual expression of knowledge structures and argument formats. Concept maps provide a complementary alternative to natural language as a means of communicating knowledge.

\section{Concept Map Research in Reading Comprehension}

Jonassen (1996) indicated that students reveal some of their best thinking when they try to express themselves graphically. Studies in long term retention tests show that students using concept mapping make more progress than those who do not (Novak \& Gowin, 1984). Both constructivist and cognitive learning theories conclude that new knowledge should be a combination of knowledge subsumed so as to be remembered and meaningful (Ausubel, 1964; Novak, 1998; Krashen, 1993; Smith \& Ragan, 1999). Concept mapping embodies this idea by making conceptualizations clear to help learners understand the relationships among concepts. Research reveals that concept mapping helps learners many ways, and it is especially effective in encouraging student reading comprehension in aspects of developing summaries, enlarging their vocabulary, augmenting self-awareness in learning, 
reviewing for an exam, and in reading as a whole (Chang, Chen, \& Sung, 2002).

Hibbing and Rankin-Erickson (2003) maintain that instructors can use mapping strategies instead of the practice of just testing students on word definitions. They reveal that through visual description of words, mapping strategies can activate students' prior knowledge and help them understand relationships with newly introduced vocabulary words. Students can develop related rather than isolated word knowledge, learn and master a group of words instead of just one single word, and develop skills in differentiation concepts as well as defining words.

Concept mapping forces students to think meaningfully about the content domain so as to identify and verify important concepts, classify concepts, describe the relationship between concepts and assess its meaning, analyze the nature of the relationship, and form the link or connection which engages the most critical thinking (Jonassen, 1996). Depending on how concept mapping is utilized in an instructional context, it can change the encoding process that in turn affects student performance and the learning outcome. As a learning strategy in reading, concept mapping supports organizational strategies, summarizing strategies, enlarging vocabulary, encouraging comprehension, and helping learners think and organize their thoughts cognitively.

Aside from summarizing readings, organizing materials, reviewing for exams, enlarging vocabularies and writing essays, concept mapping helps students think logically and scientifically. Besides, maps help learners practice collaboration, explore knowledge, and reflect on what they have learned. Many people regard drawing a concept map as participating in a brainstorming session. As ideas are put down on paper without criticism, the ideas become clearer and the mind becomes free to understand new ideas. The new ideas can be linked to ideas on paper; they may also activate new associations leading to even more new ideas. Concept mapping embodies the philosophy of constructivism, for the process of merely creating a concept map forces students to organize, categorize, analyze, evaluate, and reason actively and critically; thus learning becomes active. Mapping is thinking (Buckley-Hanf, 1971; Muccinati, 1988; Muth, 1987). In order to learn and remember, we must place information in a structured pattern. A concept map provides that structured pattern with all the details connected to more inclusive ideas. A word or label can bring to mind the connections among pieces of new information and among new concepts and prior knowledge. Mapping

Doi: 10.12816/0052309 
promotes meaningful learning rather than rote learning, the information or knowledge will be retained longer (Shuster, 2002).

\section{Computer-Based Applications of Concept Maps}

Educational technological devices have provided traditional Saudi EFL learners with effective, vivid, active and authentic means of transcending the limitations of time and space imposed by the classroom environment. These technological devices which are established in almost all schools in what is called Leaning Resources Centers ( LSC ) help enhance student motivation and increase their interest in learning. The researcher has chosen computer-based concept mapping instruction for the study because of the advantages to create the situation and environment of language activities, providing topics and content for cultivating background knowledge to enhance reading comprehension. Jonassen and Grabinger (1990) pointed out that concept mapping tools are a special kind of technology tool that were designed for the advantage of both learning and instruction. There are many technical advantages to aid learning such as: ease of adaptation and manipulation, linking and conversion, wider communication, and storage and color.

Anderson-Inman and Seitz (1993) compare instruction by using concept mapping of various websites introducing theses computer-based concept maps ( CBCM ) on the internet ( See Appendix B ) with that of the traditional approach by paper and pencil. They found that using enabled students to make any changes to the maps because revisions are achieved quickly and easily. Computer-supported concept mapping tools give students freedom to point and drag a concept or group of concepts to anywhere they like on the map and update any links they want automatically. After a concept map is made by computer, the formats or projects can be stored, sent, used, printed, and deleted just as any computer file (West, 1996). Computer-based concept mapping is unique and reliable. A concept map created on a computer allows students to send them as attachments with e-mail information and if necessary, they can even send maps in web formats so that more people can see and benefit from it than just concept maps done with pen and paper. Computer-assisted concept maps enhance the possibilities as communication tools with more people involved (Gaines \& Shaw, 1995). They are especially effective to be used as a collaborative tool to encourage group work and project-based activities by encouraging students to share knowledge, discuss questions, and integrate information in order to construct a more cohesive and comprehensive knowledge structure (Hibbing \& Rankin-Erickson, 2003). Computerbased concept mapping makes retrieval easier and is especially 
important if concept maps are used on a large scale (Wang \& Lee, 1993). Computer-assisted maps are pleasing to the eyes through precise drawing and consistent use of color. Computer-assisted mapping instruction makes it possible to deal with large concept maps that are difficult to develop in paper and pencil form.

\section{METHODOLOGY}

From literature reviewed, the researcher believes that if students are provided with computer concept mapping instruction while processing reading materials, activation of an appropriate schema would be facilitated, prior knowledge would be applied, and reading behavior might be changed from basically traditional book-dependent style to an automatic and collaborative style, thus, student reading comprehension may be improved. This contains three parts: the first part provides the location for the study, the second explains the design for the study, and the third describes the research methods used in the study.

\section{Location and Time for the Study}

The study was conducted in the first semester of the academic year 2016-2017 at Abdel Aziz Al Saud Official Language School in Cairo. English is taught as a foreign language, and it is required of every student. The duration of the study was eight weeks. Qualified EFL instructors were willing to undertake the instructional tasks required for the eight week duration of the study. Furthermore, traditional program was offered at the school are consistent with the content of this study. Both teachers were given instructions on how to deal with both modes of teaching.

\section{Information about the Participants}

The study consisted of 40 students who were divided into two groups with 20 students in each group. Both traditional and concept mapping reading instructions were conducted at the two classes for the 40 first-year students in each of two classes. The textbook used was HELLO , STUDENT'S BOOK - TERM 1( 2016 - 2017 ) Edition. The two classes of students were randomly selected from classes . The students' ages ranged from 14 to 16, which helped illustrate different learner life experiences. Participants shared similarities in that they all had been trained to learn English as a foreign language in the traditional method which was mostly book and instructor-dependent. The similarity in student learning experiences and their disparate backgrounds provide a roughly equivalent starting point in this study.

\section{Design for the Study \\ Study Hypotheses}

Doi: $10.12816 / 0052309$ 
1. There is no significant difference in the reading comprehension scores of students taught by traditional reading instruction as compared with the scores of students taught by concept mapping reading instruction.

2. There is no significant difference in the scores on attitude toward instructional mode of students taught by traditional reading instruction compared with the scores of students taught by concept mapping instruction.

\section{Study Tasks}

During the eight weeks, two types of reading instructions were implemented in both classes: traditional reading for the class of the 20 first-year students, concept mapping instruction for the experimental first-year class of 20 students . This information was demonstrated by way of concept maps developed from the reading. The traditional classes were provided with traditional reading instruction in which emphasis was placed on comprehension of materials through decoding linguistics with grammatical structure and vocabulary. Two instructors conducted both classes twice a week throughout the eight weeks for four hours a week.

\section{Study Materials \\ Instructional Steps}

Based on the syllabuses for both traditional instruction (Appendix A) and concept mapping instruction (Appendix B), the study was conducted by two EFL instructors who were willing to cooperate in the study. During the eight-week study, the instructors and participants met twice a week. Following the syllabi, the instructors trained the traditional participants with traditional reading skills and the concept mapping participants with concept mapping reading skills.

\section{Variables}

Independent variables, types of reading instruction applied; and dependent variable, (a) the scores in the reading comprehension based on the main idea, subordinate idea, and reading between the lines and (b) the scores of attitude survey.

\section{Concept Mapping Reading Instruction}

Concept mapping reading instruction was conducted to create maps for comprehension (Appendix B). It was based on meaningful and schemata learning theories of Novak and Coady for the purpose of improving student reading comprehension. 


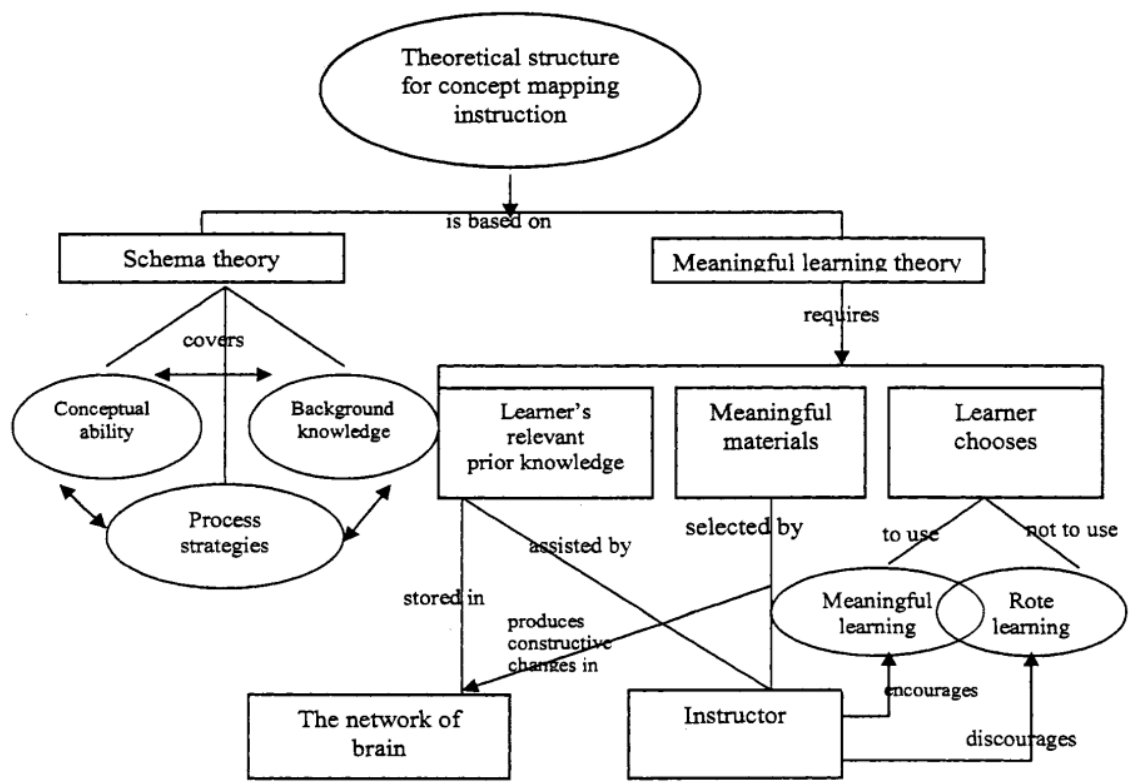

Figure (5 ) Theory Structure for Concept Mapping Reading Instruction

The intent of this instruction was to enable students to comprehend better through combining traditional reading with concept mapping development; to change student reading behavior from the traditional book/instructor-centered to an active to develop student ability in reading comprehension by combining new knowledge with the old. Instructional methods in the eight weeks was based on the combination

1. Visiting concept map web pages shown online. ( Appendix B )

2. Reading comprehension.

3. Concept maps creating by students

With a computer, students organized the main idea, subordinate ideas, and ideas deduced from reading between the lines by putting the main idea of the reading in the top level boxes of their concept maps, subordinate ideas in the subordinate level boxes of the map, and deduced meaning connected by crossing level link boxes. The finished maps created by the students were collected so as to obtain the reading data for the study.

\section{Traditional Reading Instruction}

Based on Goodman's (1973) psycholinguistic reading theory, traditional reading instruction captured the spirit of both bottom-up and top-down processes of decoding meaning from the printed page. It included a set of efficient comprehension strategies which was roughly diagrammed below:

Doi: 10.12816/0052309 


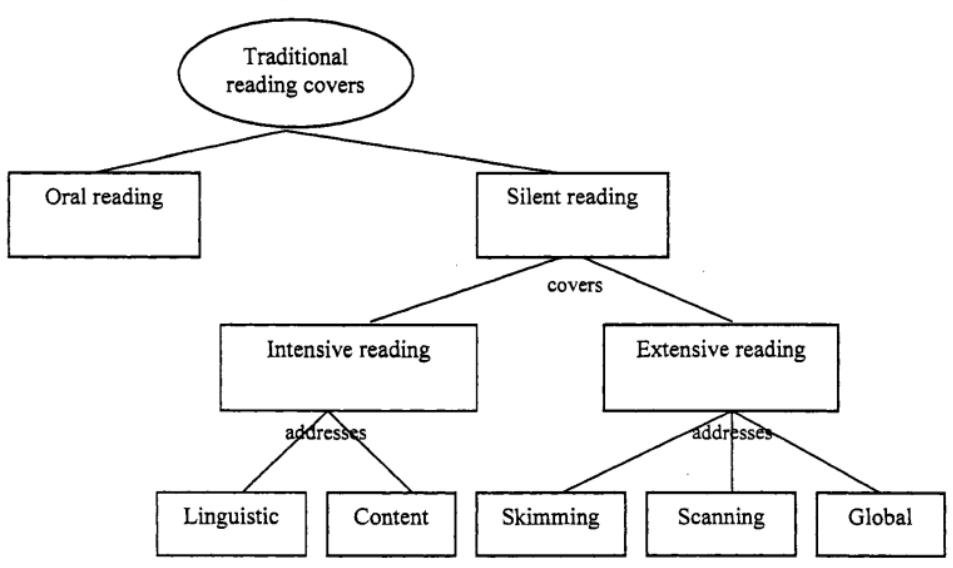

Figure (6 ) Traditional Reading Structure

The goal of traditional instruction was to enable students to read faster and comprehend better by enlarging vocabularies, reinforcing grammatical structure, and developing efficiency in reading through reading comprehension and doing multiple choice tests. Instructional methods for traditional reading classes were:

1. Identify the purpose in reading. When processing reading material, participants are instructed to identify the purpose in reading for comprehension. By doing so, they know what they are looking for and can weed out potential distracting information.

2. Use bottom-up or top-down reading methods for comprehension. This strategy is used to give participants some step-by-step reading skills for word, grammar, and structure rules to help them comprehend.

3. Use efficient silent reading techniques for relatively rapid comprehension. The instructor uses this strategy to encourage learners to read more efficiently and to visually perceive more than one word at a time.

4. Skimming and scanning. For a better and faster comprehension, participants are encouraged to quickly run their eyes across a whole reading to get the gist, main topic, or supporting ideas. They are also told to quickly search for some particular piece or pieces of information.

5. Guessing. Guessing is employed to enhance continuous reading comprehension without too much disruption of consulting a dictionary for meaning. Apart from guessing the meaning of new words, participants are also encouraged to guess the grammatical 
relationship, discourse relationship, cultural reference and content messages while handling the reading material.

6. Vocabulary analysis. To get meaning out of reading, students are also instructed to look for vocabulary prefixes, suffixes and roots that may give clues. Also they are to look for grammatical contexts and semantic contexts that may signal information.

7. Read between the lines and summarize a reading. To deduce meaning from context of a reading and summarize in a few words.

\section{Assessment Methods and Statistical Analysis}

Two methods were used to assess the study: one was attitude survey and the other was scoring on reading abilities in the main idea, subordinate ideas and reading between the lines in the ten sets of EFL readers.

\section{Survey}

An attitude survey was given at the end of the eight week study to determine student satisfaction and dissatisfaction of concept mapping as an instruction associated with reading. Participants completed the survey (Appendix C) developed by the researcher.The survey contained 20 questions regarding participant level of satisfaction or dissatisfaction of the eight-weeks of instruction, methods, and assessment used in the study. Likert-type scale items required respondents to rate on a scale of 1 to 4 with various aspects of the study from "strongly agree" to "strongly disagree" and these ratings were assigned the value of: strongly agree $=4$, agree $=3$, disagree $=2$, and strongly disagree $=1$. A survey was included because it provided respondents with the opportunity to express their opinions, resulting in more variable scores about the usefulness and effectiveness of the concept mapping instruction. The survey was tested by a few individuals before putting it into use for all participants so that the researcher could find out whether it was necessary to make any language changes regarding various aspects of the survey.

\section{Reading Scoring}

Both concept mapping reading and traditional reading were assessed (Rafferty \& Fleschner, 1993) on student abilities in three reading areas: main idea finding, subordinate idea finding, and reading between the lines. Reading for both groups will be scored as follows:

1. Main idea finding in traditional reading is equal to the top level of concept mapping development (both score 3 points for one main idea). 1 valid main idea finding ( 3 point each $)=3$ marks.

Doi: 10.12816/0052309 
2. Subordinate idea finding in traditional reading is equal to the lower level of concept mapping reading (both score 2 points for each subordinate idea). 10 valid subordinate idea finding ( 2 point each ) $=20$ marks .

3. Reading between the lines in traditional reading is equal to the ability in building cross level linkage in concept mapping reading (both score 5 points for reading between the lines). 1 cross-link=reading between lines ( 5 points ) 5 marks.

The total is 28 marks.

\section{Data Analysis}

The analytical method of independent samples t-test was used to show whether there was any difference in the three reading areas between the two instructions. One-way ANOVA was used to tell whether there was any difference in the three reading areas within each instruction. The independent variable was the type of instruction (i.e., concept mapping reading, traditional reading). The dependent variable was the reading scoring results in the 10 sets of readings on main idea, subordinate idea and reading between the lines.

Likert attitude survey toward different modes of instruction was analyzed and answered by using the independent samples t-test. Participants were asked to rate each item from strongly disagree to strongly agree. Ratings were summed and divided by the number of items completed (i.e., [item 1+item $2+. .+$ item 20] / 20). The independent variable was mode of instruction. The dependent variable was the attitude score of the survey. The alpha level was 0.5. All data were analyzed with the Statistical Package for the Social Sciences (SPSS) version 14.0.

\section{RESULTS}

This part presents the results of the analysis of main idea reading, subordinate ideas reading and reading between the lines of both participants taught by concept mapping and traditional reading instructions. It also presents the results of the analysis carried out on participants' attitudes in survey questions regarding concept mapping and traditional readings.

\section{Results of Main Idea Reading}

Is there a significant difference in scores on main idea reading between concept mapping and traditional instructions? Descriptive statistics in main idea reading are shown in table 1 and the result of the independent samples t-test analysis is shown in Table 2 The scores for concept mapping instruction ranged from 24 to $30(M 26.1, S D=1.97)$. 
Meanwhile, the scores for traditional instruction ranged from 24 to 30 $(M=25.7, S D=1.81)$.

Independent samples t-test was conducted to examine differences between the means in main idea reading of the two instructions. The test was not significant, $\mathrm{t}(3 \mathrm{8})={ }^{\cdot} \cdot 751, \mathrm{p}=.457$ (Table 2 ), which indicated that there was no significant difference between the mean scores of participants in concept mapping and traditional instructions for main idea reading. Participants of both instructions revealed approximate reading ability in main idea reading.

Table1 :Descriptive Statistics of Main Idea Reading for Both Instructions

\begin{tabular}{|l|l|l|l|}
\hline & $M$ & $S D$ & $n$ \\
\hline Concept Mapping & 26.10 & 1.97 & 20 \\
\hline Traditional & 25.65 & 1.81 & 20 \\
\hline
\end{tabular}

Table 2 :T- Test Results of the Three Reading Areas and Attitude Survey for Both Instructions

\begin{tabular}{|l|l|l|l|l|l|l|}
\hline & & & $d f$ & & $t$ & \multicolumn{1}{c|}{$\mathrm{p}$} \\
\hline Total Scores & & & 38 & - & 1.109 & .275 \\
\hline Main Idea Reading & & & 38 & & .751 & .457 \\
\hline $\begin{array}{l}\text { Subordinate Idea } \\
\text { Reading }\end{array}$ & & & 38 & & - & 1.781 \\
\hline $\begin{array}{l}\text { Reading between the } \\
\text { Lines }\end{array}$ & & $:$ & 38 & & -.196 & .846 \\
\hline Attitude Survey & & & 29.7 & & 5.82 & $.000 * * *$ \\
\hline$* p<.05 * * * p<. O O l$ &. & & & & & \\
\hline
\end{tabular}

\section{Results of Subordinate Idea Reading}

Is there a significant difference in scores on subordinate idea reading between the two instructions? This reading area was examined using independent samples t-test. The descriptive statistics are shown in Table 3 and the result of the independent samples ttest analysis is shown in Table 2. The scores for concept mapping instruction ranged from 78 to $88(M=82.8, S D=2.78)$. Meanwhile, the scores for traditional instruction ranged from 78 to $88(M=84.6, S D=3.56)$. The test was still not significant in scores on subordinate idea reading, $\mathrm{t}(38)=$ $l$. $78 l, p=.083$ (Table 3 ). This indicated that in subordinate idea reading, participants of both instructions revealed approximate reading ability, for no significant difference was found between the mean scores of 
participants in concept mapping and traditional instructions for subordinate idea reading.

Table 3:Descriptive Statistics of Subordinate Idea Reading for Both Instructions

\begin{tabular}{|l|l|l|l|}
\hline & $M$ & $S D$ & $n$ \\
\hline Concept Mapping & 82.8 & 2.78 & 20 \\
\hline Traditional & 84.6 & 3.56 & 20 \\
\hline
\end{tabular}

\section{Results of Reading between the Lines}

Is there a significant difference between scores of concept mapping and traditional instructions in reading between the lines? The descriptive statistics are shown in Table 4 and the result of the independent samples t-test is shown in Table 2 above. The scores for concept mapping instruction on reading between the lines ranged from 25 to $40(M 34.5, S D=4.26)$. The scores for traditional instruction on reading between the lines ranged from 30 to $40(M=34.8, S D=3.80)$.

This reading area was examined using the same instrument of independent samples t-test. The test was still not statistically significant for mean scores, $\mathrm{t}(38)=-.196, p=.846$ (Table 2). The result indicated that concept mapping participants had the same reading ability in reading between the lines with those of the traditional instruction.

Table 4 : Descriptive Statistics of Reading between the Lines for Both Instructions

\begin{tabular}{|l|l|l|l|}
\hline & $M$ & $S D$ & $n$ \\
\hline Concept Mapping & 34.50 & 4.26 & 20 \\
\hline Traditional & 34.75 & 3.80 & 20 \\
\hline
\end{tabular}

\section{Results of Total Scores for Both Instructions}

Is there any significant difference between the mean scores of concept mapping and the traditional instructions in the main idea, subordinate idea and reading between the lines? The independent samples t-test was conducted to test it. The descriptive statistics are shown in Table 5 and the result of the $t$ - test analysis is shown in Table 2 above.

The total scores for concept mapping instruction in the three reading areas of main idea reading, subordinate idea reading and reading between the lines ranged from 44.67 to $50.33(M=47.80, S D=1.63)$. Meanwhile, the total scores for traditional instruction in the three reading areas ranged from 46.33 to $51.00(M=48.33, S D=1.40)$. The 
test was not significant, $\mathrm{t}(38)=-1.109, p=.274$. This indicated the approximate reading ability in total scores of both participants and the research results agreed with the first null hypothesis of the study.

Table 5 :Descriptive Statistics of Total Scores for Both Instructions

\section{Results of Attitude Survey}

\begin{tabular}{|l|l|l|l|}
\hline & $M$ & $S D$ & $n$ \\
\hline Concept Mapping & 47.80 & 1.63 & 20 \\
\hline Traditional & 48.33 & 1.40 & 20 \\
\hline
\end{tabular}

The second hypothesis stated that there is no significant difference in the scores of students' attitudes between traditional reading instruction and concept mapping instruction. Descriptive statistics are shown in Table 6 and the result of the independent samples t-test is shown in Table 2 above. The survey contained 20 simple items to measure students' attitudes. Participants were asked to rate each item from strongly disagree which equaled 1 point to strongly agree which equaled 4 points. Ratings were summed and divided by the number of items completed (i.e., [item $1+$ item 2 +. . + item 20] / 20) (Appendix D). Scores for concept map reading ranged from 56 to $68(M=61.5, S D$ = 3.56). Scores for traditional instruction ranged from 53 to 59 ( $M=$ 56.2, $S D=1.98$ ).

Participants' attitudes were examined using independentsamples $t$ test and the result was statistically significant, $\mathrm{t}(29.7)=5.82, \mathrm{p}$ $=.000$. The attitude results countered the research hypothesis, thereby indicating that concept mapping participants had a significantly higher attitude rating compared with those of the traditional participants

Table 6:Likert-type Scale \& Descriptive Statistics of Attitude Survey for Both Instructions

\begin{tabular}{|l|l|l|l|l|l|l|l|}
\hline & $\begin{array}{l}\text { Likert- } \\
\text { type }\end{array}$ & Scale & & & $M$ & $S D$ & $n$ \\
\hline 1 & 2 & 3 & 4 & & \multicolumn{4}{|l|}{} \\
\hline & & & & $\begin{array}{l}\text { Concept } \\
\text { Mapping }\end{array}$ & 61.45 & 3.56 & 20 \\
\hline SD & D & A & SA & Traditional & 56.15 & 1.98 & 20 \\
\hline
\end{tabular}

Note. $\mathrm{SD}=$ Strongly Disagree, $\mathrm{D}=$ Disagree, $\mathrm{A}=$ Agree, $\& \mathrm{SA}=$ Strongly Agre participants

Attitude results countered the hypothesis and mapping higher point value than those of the traditional. This is because concept mapping participants gave higher rating (between agree $=3$ points to 
strongly agree $=4$ points) to two types of survey questions. They rated higher to such questions as (6) the instruction helped me bring out more prior knowledge into reading comprehension and (7) the instruction helped me little to learn how to read between the lines. They also rated higher such survey questions as (8) the instruction contained reasonable blend of explanation and practice and (13) instruction made me feel that instructor's responses were important. Their preference of survey question (6) and (7) type, on the one hand, indicated positive attitude of participants on concept mapping reading because these items were designed to determine the effectiveness of concept mapping instruction. At the same time, on the other, we can see from their preference of questions (8) and (13) type that their attitudes were still influenced by traditional instruction because traditional students depend more on the roles played by teachers, textbooks and other traditional resources and these items were deigned to determine the extent of usefulness of the traditional instruction (Appendix C).

Results of ANOVA for the Three Readings within Each Instruction Closely linked with $t$-test, one-way ANOVA (Table 7) was also conducted to test whether there were any differences between the mean scores of main idea reading, subordinate idea reading and reading between the lines within concept mapping. Table 4.8 provides the oneway ANOVA results. The one-way ANOVA test revealed there was a significant difference in the three readings for the concept mapping group $\quad[F \quad(2, \quad 57)=$ 43.07, $p<.001]$. To obtain where the differences existed, a Tukey's post hoc test was conducted. This test revealed there were significant differences between both main idea reading (MIR) and reading between the line (RBL), and subordinate idea reading (SIR) and reading between lines $(\mathrm{RBL})$, which indicated that participants read better in main idea and subordinate idea readings.

A one-way ANOVA test conducted for the traditional instruction showed there was a significant difference between the three reading areas, $[F[2,57]=.45 .36, \mathrm{p}<.001]$. To obtain where the differences existed, a Tukey' s post hoc test was conducted. This test revealed there were significant differences between both MIR and RBL, and SIR and RBL. 
Table 7 : One-Way ANOVA Test for MIR, SIR and RBL within Each Instruction

\begin{tabular}{|l|l|l|l|l|l|}
\hline & $\begin{array}{l}\text { Sum of } \\
\text { Squares }\end{array}$ & df & $\begin{array}{l}\text { Mean } \\
\text { Square }\end{array}$ & F & Sig. \\
\hline Traditional & & & & & \\
\hline $\begin{array}{l}\text { Between } \\
\text { Group }\end{array}$ & 3232.13 & 2 & 1616.07 & 45.36 & $.000 * * *$ \\
\hline $\begin{array}{l}\text { Within } \\
\text { Group }\end{array}$ & 2030.80 & 57 & 35.33 & & \\
\hline Total & 5262.93 & 59 & & & \\
\hline Concept & & & & & \\
\hline $\begin{array}{l}\text { Between } \\
\text { Group }\end{array}$ & 3547.20 & 2 & 1773.60 & 43.07 & $.000 * * *$ \\
\hline $\begin{array}{l}\text { Within } \\
\text { Group }\end{array}$ & 2347.20 & 57 & 41.18 & & \\
\hline Total & 5894.40 & 59 & & & \\
\hline$* \mathrm{p}<.05 * * * \mathrm{p}<001$ & & & & \\
\hline
\end{tabular}

Summary

By using independent samples t-tests, this part examined the study results of reading areas of main idea reading, subordinate idea, reading between the lines and participants' attitude for concept mapping and traditional reading instructions. One-way ANOVA was also conducted to test whether any difference existed between the three reading areas within each instruction. By t-test, statistical analysis revealed no significant difference between the two instructions in main idea reading, subordinate idea reading and reading between the lines. However, differences were found in participants' attitudes for the two instructions. A one-way ANOVA test conducted for both concept map and traditional instruction showed there was a significant difference between reading between the lines and main idea reading and reading between the lines and subordinate idea reading within each instruction.

\section{Discussion}

Based on statistical results, this part discusses some possible reasons for the results revealed in four sections. The first section discusses possible reasons revealed by statistics in main idea, subordinate idea and reading between the lines of both instructions. The second analyzes the survey attitudes of participants for both instructions. The third section presents a few future research considerations on concept mapping instruction. The last is a brief summary that ends the study.

Doi: $10.12816 / 0052309$ 
Discussion on Main Idea, Subordinate Idea and Reading between the Lines of the Two Instructions

Is there any difference in comprehension of main idea, subordinate idea and reading between the lines of the two instructions? Independent samples t-tests revealed no significant difference between them. The mean in main idea reading for concept mapping instruction was 26.1 ( $S D=1.97)$, while 25.7 ( $S D=1.81)$ for traditional instruction. The mean in subordinate idea reading for concept mapping instruction was $82.8(S D=2.78)$, while $84.6(S D=3.56)$ for traditional instruction. The mean in reading between the lines for concept mapping instruction was $34.5(S D=4.26)$, while $34.8(S D=3.80)$ for traditional instruction. The statistical approximation in scores of the three reading areas indicated that participants of both instructions had almost the same reading ability in main idea, subordinate idea and reading between the lines.

An important reason why concept-mapping participants did not score much better than traditional participants might be traced to the level of comfort and proficiency with technology for concept mapping participants. Although Inspiration is like an outlining program which does diagrams and although it is one of the most user-friendly pieces of software, it still takes time for the first time EFL students to get familiar with it. It takes practice for EFL students even to label the arrows, draw boxes and get familiar with the Inspiration menus to make a good map.

Before the eight-week data collecting, one week was allowed for concept mapping participants to get familiar with the work on websites organizers using PowerPoint Presentation. Four hours were spent on the explanation for participants to get familiar with the basic functions of the software and on practicing skills, drawing maps, getting familiar with technology connected with the software and visiting mapping webpages at the Resources Learning Center at the school.

Concept mapping participants might feel proud of what they had accomplished in the eight-week study with educational technology. Some of them might have begun to enjoy the skills concept mapping has put in their hands. But, the test did not reveal significant differences in mean scores on the three reading areas between the two instructions. One week of training time might not be long enough for participants to completely get over their nervousness facing new technology. Some of the participants might still feel uncomfortable and not proficient enough reading with new technology after two weeks of training time. Some participants might still have problems finding their way around computers, problems using mapping web-pages and problems working 
with the basic computer-key functions with confidence. Creating maps for ideas to interpret and communicate and modifying images with graphical software was a new learning mode for mapping participants.

Meanwhile, traditional reading is a long-standing instructional mode well practiced in the present EFL setting. The traditional participants were used to and felt comfortable with the traditional reading techniques. They were good at reading strategies on the main idea, subordinate idea and reading between the lines because the traditional instruction has been training students' basic linguistic skills for many years .The language requirements and instruction practiced have laid a solid linguistic foundation which, in turn, has paved the way for traditional participants to score well in main, subordinate idea and reading between the lines. Classroom practice has taught reading skills and required students to master a set of reading techniques to increase reading comprehension. Trained by this instructional mode, many students were good at and comfortable with identifying main idea, subordinate idea and reading between the lines for comprehension by using efficient silent reading techniques of skimming, scanning, guessing and vocabulary analysis. The long-time practiced traditional instruction discussed above might be an important reason that enabled traditional participants to score well on the three reading areas.

\section{Discussion on Attitude Survey}

Is there any significant difference in participants' attitudes between concept map instruction and traditional instruction? Statistical finding revealed significant difference on attitudes between participants of the two instructions. Participants for concept map reading $(M=61.45$, $S D=3.56)$ had a higher attitude than those of the traditional $(M=56.15$, $S D=1.98$ ). Mapping participants rated higher in such survey questions as (6) the instruction helped me bring out more prior knowledge into reading comprehension and (7) the instruction helped me read between the lines. They also favored survey questions on (8) the instruction contained reasonable blend of explanation and practice and (13) instruction made me feel that instructor's responses were important. Their preference of survey question (6) and (7) type, on the one hand, indicated positive attitude of participants on concept mapping reading. At the same time, on the other, we can see from their preference of questions (8) and (13) type that their attitudes were still influenced by traditional instruction because traditional students depend more on the roles played by teachers, textbooks and other traditional resources in learning. Why did the mapping participants favor technology use with a strong traditional feature? The following aspects are discussed from the

Doi: 10.12816/0052309 
point of view of traditional instruction.

Students in Egypt give much attention to reading and writing. To meet this need, curriculum developed, strategies applied and assessments used have been more in favor of reading than in other linguistic aspects in EFL learning. According to EFL curriculum in Egypt, English Syllabi and English instructional goals at the school level is to train the students to have a strong reading ability. The language requirements have laid a solid linguistic foundation, which has further paved the way for participants to get used to traditional learning supported by concept mapping. Classroom practice has been requiring students to master a set of reading techniques to increase reading comprehension. Trained with this instructional mode, many students are good at and comfortable with identifying the main idea in reading by using efficient silent reading techniques in skimming, scanning, guessing and vocabulary analysis. The practice of such instructional mode influenced participants' attitudes on functions of technology, textbooks and instructor. Traditional curriculum and assessment have guided EFL learning and shaped students' learning attitudes, learning styles and learning results, which reflected from survey attitudes of concept mapping participants.

The unified assessment and its scoring methods are also reasons to influence participants' attitude in survey questions on functions of technology and textbooks and roles played by instructors in the current study. Encouraged by technology, mapping participants had an approximate reading score in main idea, subordinate idea and reading between the lines to those of the traditional instruction. Influenced by traditional instruction and practiced by concept mapping, concept mapping participants gave favorable rating to the function of technology as well as the roles played by instructor and textbooks.

Personal characteristics are another reason for concept mapping participants to have such attitude on functions and roles played by instructor, textbooks and technology. These characteristics are determined by the culture into which learners are born and in which learners are brought up. Dependency on textbooks and instructors is closely linked with students' cultural background. A person's cultural background is even more influential in affecting a student's learning style and learning attitude.

Independent samples t-tests did not reveal any difference between the two instructions in the three reading areas, but it does not mean concept mapping instruction is not effective at all in an EFL 
setting. From participants' higher rating on survey question type (1) and (2), researcher found participants' preference on concept mapping instruction in prior knowledge application while handling the new knowledge (Ausubel, 1964; Novak, 1998) and critical thinking ability in making judgment on the authenticity, accuracy and value of knowledge. One-way ANOVA revealed significant difference in main idea reading, subordinate idea reading and reading between the lines. Both data revealed by one-way ANOVA and attitude preference by survey indicated learning interest brought about by educational technology. One-way ANOVA statistics and attitude preference further indicated the educational implications of concept mapping in helping EFL students to think critically and to apply prior knowledge while learning new knowledge (Ausubel, 1964; Krashen, 1993; Novak, 1998; Smith \& Ragan, 1999).

\section{Considerations for Future Research}

Based on discussion of research results above, four considerations are suggested for future technology-based concept mapping instruction in an EFL setting. To raise students' level of comfort and proficiency with technology, the first consideration is to provide longer training periods for both EFL students with the help of technology. To read with a new technology and to help students to be more skillful and comfortable with technology, it will be productive and helpful for future research to provide more opportunities in formal training which have longer training period, during which time, students practice using the programs in much greater details and instructor helps students to integrate them into the real day to day concept mapping study. The second consideration is to combine traditional instruction with the help of technology for an EFL learning situation. Attitude survey revealed that concept mapping participants had a significant higher attitude rating than those of the traditional. Careful analysis of their attitudes found that students favored concept mapping reading with a strong preference of traditional instruction. This indicated the positive roles played by instructors and textbooks in learning. To raise students' learning and to enhance instruction, it is practical and realistic to maintain an EFL instructional style by integrating educational technology into traditional instruction.

The third consideration is to investigate how EFL learners in a technology-based learning situation change learning behavior from totally instructor and textbook dependency to a multiple-sourcedependency of teachers, students and technology so that their learning will be more enriched. As revealed by discussion above, EFL learners as

Doi: 10.12816/0052309 
social and cultural products need constant guidance from textbooks and teachers. They seek approval and reassurance from teachers. They need constant help from teachers. They are accustomed to and feel more comfortable with receiving knowledge as given by teachers. How can an instructor help such EFL learners learn independently by assuring themselves with the help of technology as a tool? And how can an instructor help them seek information and knowledge not just in textbooks, dictionaries and instructors, but also prior knowledge stored in their own mind and knowledge brought about by technology. This is an area that still needs investigation in future technology-based EFL study.

The last consideration is to provide more workshops and training opportunities for the EFL instructors so that they will be more technologically proficient to enhance technological instruction. 


\section{REFERENCES}

1. AlKahtani, S., \& Abaihassan, K. (1999). MacReader and storyboard programs in ESL reading classrooms. CALL-EJ Online, 3(2). Retrieved March 16, 2007, from http ://iteslj .org/Techniques/AlKahtani-ComputerReading

2. Anderson-Iriman, L., \& Zeitz, L. (1993). Computer-based concept mapping: Active studying for active learners. The Computing Teacher, 21(1), 1-5.

3. Anderson-Inman, L., Ditson, L., \& Ditson, M.(1998). Computer-based concept mapping Promoting meaningful learning in science for students with disabilities. Information Technologies and Disabilities Journal, Special K-12 issue, ITDVO5N1-2, article 2.

4. Anderson, R. C. (1977). The notion of schemata and the educational enterprise: General discussion of the conference. In C. Richard, R. I. Anderson, \& W. E. Montague (Eds.), Schooling and the acquisition of

knowledge (pp. 415 -431). Hilisdale, NJ: Lawrence Erlbaum Associates.

5. Ausubel, D. A. (1963). Cognitive structure and the facilitation of meaningful verbal learning. Journal of Teacher Education, 14, $217-$ 221.Ausubel, I). A. (1964).

6. Ausubel, D. A., Novak, 3. D., \& Hanesian, H. (1978). Educational psychology: A cognitive view. New York: Holt, Rinehart and Winston.

7. Bikowski, D., \& Kessler, G. (2004). Making the most of discussing boards in the ESL classroom. TESOL Journal, 11(3), 27-30.

8. Brown, H. D. (1994). Teaching by principles: An interactive approach to language pedagogy. Upper Saddle River, NJ: Prentice Hall Regents.

9. Brumfit, C. 3., \& Roberts, 3. T. (1983). Short introduction to language and language teaching. London: Batsford Academic and Education Ltd.

10. Buckley-Hanf, M. (1971). Mapping: A technique for translating reading into thinking. Journal of Reading, 14, 225-230.

11. Chang, K., Chen, I., \& Sung, Y. (2002). The effect of concept mapping to enhance text comprehension and summarization. The Journal of Experimental Education, 71(1), 5-23.

12. Chun, D. M., \& Plass, 3. L. (1996). Facilitating reading comprehension with multimedia. Language Learning \& Technology, 24(4), 503-5 19.

13. Chun, D. M., \& Plass, J. L. (1997). Research on text comprehension in multimedia environments. Language Learning \& Technology, 1(1), 60-81. 
14. Coady, 3. (1979). A psycholinguistic model of the ESL reader. In R. Mackay, B. Barkman, \& R. R. Jordan (Eds.), Reading in a second language (pp. 5- 12).

15. Rowley, MA: Newbury House Publisher.Culver, L. C. (1991). Improving reading speed and comprehension of ESL students with the computer. Practicum Papers, Nova University.

16. Driscoll, M. (1997). An Inquiry into the spontaneous transfer of problem-solving skill. Contemporary Educational Psychology, 22, 472-494.

17. Freiermuth, M. R. (2004). Internet chat: Collaborating and learning via conversations. TESOL JOURNAL, 2(3), 3 6-40.

18. Gaines, B. R., \& Shaw, L. G. (1995). Web map: Concept mapping on the web, Proceedings of WWW4: Fourth International World Wide Web Conference. RetrievedApril 20, 2007, from http://ksi.cpsc.ucalgary.caJarticles/abstracts.html\#ConceptMaps

19. Goodman, K. S. (1967). Reading: A psycholinguistic guessing game. Journal of The Reading Specialist, 6(1), 126-135.

20. Goodman, K. S. (1971). Psycholinguistic universals in the reading process. In P. Pimsleur, \& T. Quinn (Eds.), The psychology of second language Learning (pp. 135-142). Cambridge: Cambridge University Press.

21. Goodman, K. S. (1973). On the psycholinguistic method of teaching reading. In F. Smith (Ed.), Psycholinguistics and reading (pp. 177 182). New York: Holt, Rinehart and Winston

22. Graesser, A. C., \& Clark, L. F. (1985). Structures and procedures of implicit knowledge.

23. NJ: Ablex. Halliday, M.A. K., \& Hassan, R. (1989). Language, context, and text: Aspects of language in a social- semiotic perspective. Oxford: Oxford University Press.

24. Hibbing, A. N., \& Rankin-Erickson, J. L. (2003). A picture is worth a thousand words: Using visual images to improve comprehension for middle school struggling readers. The Reading Teacher, 56(8), 758.

25. Jackson, 3., Harper, K., Ruzic, R., \& O'Connell, K. (1999). Concept maps summary source data. Retrieved December, 2006, from http://www.cast.org/ncac/ConceptMaps1669.cfm

26. Jonassen, D., \& Grabinger, R. (1990). Problems and issues. In D. H. Jonassen \& H. Mandel (Eds.), Designing hypermedia for learning (pp. 3-26). London: SpringerVerlag.

27. Jonassen, D. H. (1996). Computers in the classroom: Mind tools for critical thinking. Eaglewoods, NJ: Menu/Prentice Hall.

28. Jonassen, D. H., \& Reeves, T. C. (1996). Learning with technology: Using computers as cognitive tools. In D. H. Jonassen (Ed.), Handbook of research for educational communications and technology (pp. 693-7 19). New York:

Doi: 10.12816/0052309 
29. Macmillan.Kaplan, R. B. (1996). Audience and voice in current Li composition texts: Some implications for ESL student-writers. Journal of Second Language Writing, 5(1), 21-24.

30. Krashen, S. (1993). The power of reading. Englewood, Colorado: Libraries Unlimited. Kulik, J. A.,Bangert, R. L., \& Williams, G. W. (1983). Effects of computer-based teaching on secondary school students. Journal of Educational Psychology, 75(1), 19-26.

31. Muccinati, J. L. (1988).Mapping the terrain: Connecting reading with academic writing. Journal of Reading, 31, 542-5 52.

32. Muth, K. D. (1987). Structure strategies for comprehending expository text. Reading Research and Instruction, 27(1), 66-72.

33. Nersessian, N. J. (1989). Conceptual change in science and in science education. Synthese, 80(1), 163-184.

34. Novak, 3. D. (1981). The use of concept mapping and Gowin's "u" mapping instructional strategies. Junior high school science, Ithaca, NY: Cornell

35. .Novak, J. D. (1984). Clarify with concept maps. The Science Teacher, 58(7), 45-49.

36. Novak, J. D. (1993). How do we learn our lesson?: Taking students through the process. The Science Teacher, 60(3), 50-55.

37. Novak, J. D. (1998). Learning, creating, and using knowledge: Concept maps as facilitative tools in schools and corporations. Mawah, NJ: Lawrence Erlbaum and Associates.

38. Novak, 3. D., \& Gowin, D. B. (1984). Concept mapping for meaningful learning. Cambridge: Cambridge University Press.

39. Nunan, D. (1989 ). Designing tasks for the communicative classroom 452.Cambridge: Cambridge University Press.

40. Rafferty, C. D., \& Fleschner, L. K. (1993). Concept mapping: A viable alternative to objective and essay exams. Reading, Research and Instruction, 3, 25-34.

41. Rumeihart, D., \& Andrew, 0. (1977). The representation of knowledge in memory. In C. Richard, J. Rand, \& E. M. William (Eds.), Schooling and the acquisition of knowledge (pp. $99-135$ ). Hillsdale, NJ: Lawrence Eribaum Associates.

42. Schneider, E. W. (1983). Veni, vidi, vici via videodisc: A simulator for instructional conversations. System, 11(1), 41-6.

43. Shuster, P. M. (2002). Concept mapping: A critical-thinking approach to care planning. Philadelphia: F. A. Davis Company.

44. Smith. F. (1985). Reading without nonsense. New York: Teachers College

Press. Smith, P. L., \& Ragan, T. J. (1999). Instructional design. Upper Saddle

River, NJ: Prentice-Hall. 
45. Wang, D., \& Lee, J. R. (1993). Visual reasoning: Its formal semantics and applications. Journal of Visual Languages and Computing, 4(4), 327-3 56.

46. West, D.B. (1996). Introduction to graph theory. Upper Saddle River, NJ: Prentice-Hall.

47. Wortliley, K. M. (1995). Learning style factor of field dependence/independence and problem solving strategies of among refugee students. In C. I. Bennet (Ed.), Multicultural education. Boston: Allyn and Bacon.

\section{APPENDIX A}

\section{APPENDIXES}

Hello ! ( English for Secondary Schools ) Year 1 Student Book

TERM 1 - Student's Book - 2005/2006 EDITION

The following Units were taught to the students during the eight week study :

1) Famous Egyptians

2) The power or the mind

3) City or countryside

4) Health and safety

5) Amazing people

6) Communications today

7) People at work

8) Great works of engineering

\section{APPENDIX B}

1-Develop Concept Map Based on Reading using concept mapping Websites

2- Visiting the following Web Pages :

-Web: http://www.graphic.org/concept.html

http://www.ncrel.org/sdrs/areas/issues/students/learning/lr1 grorg.htm

http://www.graphicorganizers.com/downloads.htm

http://www.teach-nology.com/worksheets/graphic

http://gotoscience.com/Graphic Organizers.html

http://www.eduplace.com/graphicorganizer/index.html

http://www.teachervision.fen.com/graphic-organizers/printable/6293.html

http://content.scholastic.com/browse/article.jsp?id=2983

http://www.graphicorganizers.com/downloads.htm

http://abcteach.com/directory/researchreports/graphic_organizers// 